\title{
Effect of Alpha Chromium on Long Time Behavior
}

\author{
of Alloy 718 \\ John F. Radavich \\ Materials Department - Purdue University \\ West Lafayette, IN 47907
}

\begin{abstract}
Current studies of high temperature materials have focussed on the longtime behavior of materials in an effort to extend the life of service components. High temperature materials which appear to be stable in short exposure times can become unstable when exposed in a temperature range of up to $649^{\circ} \mathrm{C}$ for times of 10,000 hours to 100,000 hours. Most alloys used in this temperature range are high $\mathrm{Cr}$ alloys and the superalloy most commonly used is alloy 718 . Whether alloy 718 is used in aerospace or other industrial applications, the behavior of $\mathrm{Cr}$ on the formation of carbides, sigma phase, or other $\mathrm{Cr}$ rich intermetallic phases plays an important role in the eventual embrittlement of the material.
\end{abstract}

Alloy 718 is limited to temperatures of $649^{\circ} \mathrm{C}$ or below because of the occurrence of large amounts of transformations of the strengthening phase $\gamma$ to the delta plate phase with the resultant loss of impact and yield strength. In ongoing longtime behavior studies of alloy 718 at $649^{\circ} \mathrm{C}$, the impact property of alloy 718 drops from $38 \mathrm{ft}$-lbs to less than $8 \mathrm{ft}$-lbs in exposures of 50,000 hours. The initial drop in impact occurs without apparent changes in the strengthening phase; however, an $\alpha C r$ phase is starting to form and grows with time of exposure.

The results of an ongoing study of the role of $\alpha \mathrm{Cr}$ on the longtime embrittled engine run turbine disks and isothermal exposed alloy 718 will be presented. The factors which affect the $\alpha \mathrm{Cr}$ formation will be discussed.

\section{Introduction}

The role of $\mathrm{Cr}$ on brittlement in high $\mathrm{Cr}$ ferritic steels has been studied extensively long before alloy 718 was developed. The impurities for these studies was the development of a phenomenon called " $885^{\circ} \mathrm{F}$ embrittlement" wherein ferritic steels developed severe embrittlement after longtime exposures in a temperature range of $700^{\circ} \mathrm{F}$ to $1000^{\circ} \mathrm{F}$.

In 1953 a structural study of ferritic alloys containing 14-17\% $\mathrm{Cr}$ and exposed for 5-34 $\mathrm{Kh}$ at a temperature of $900^{\circ} \mathrm{F}$ was reported by Fisher, Drelis, and Carroll (1). Using TEM and $\mathrm{x}$ ray diffraction they found $\alpha \mathrm{Cr}$ (a BCC Cr rich phase) formed which was correlated to the $885^{\circ} \mathrm{F}$ embrittlement. Ferritic alloys with less than $14 \% \mathrm{Cr}$ or exposure temperatures above $1100^{\circ} \mathrm{F}$ did not form the $\alpha \mathrm{Cr}$. However, at higher temperatures, sigma phase was found and was enhanced by low carbon contents and severe cold work.

Compositions like alloy 718 are extensions of ferritic type alloys with large enough additions of $\mathrm{Ni}$ to maintain a FCC matrix but also maintaining high $\mathrm{Cr}$ levels for oxidation/sulphidation resistance. Such alloys are used in a temperature range of $539^{\circ} \mathrm{C}$ to $649^{\circ} \mathrm{C}$ and do not form $\mathrm{Cr}$ carbides as are found in $\mathrm{Ni}$ base alloys. However, such alloys form, amongst other phases, $\alpha \mathrm{Cr}$ and sigma phase when exposed for longtimes in a temperature range of $539^{\circ} \mathrm{C}$ to $704^{\circ} \mathrm{C}$.

As reported by Korth (2) and Radavich (3), alloy 718 suffers some loss of yield strength and hardness but drastic loss of impact strength with exposure time and increased temperatures.

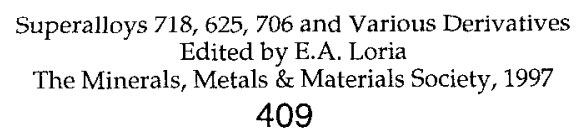


The authors have proposed that the formation and growth of $\alpha \mathrm{Cr}$ was partly responsible for the severe drop in impact strength.

Because of the similarity of the ferritic and austenitic compositions, those factors which affect $\alpha \mathrm{Cr}$ and sigma phase behavior in ferritic alloys should also affect similar phase behavior and mechanical properties behavior in alloys like 718 and alloy 625.

The objective of this study was to determine and understand the factors involved in the formation of $\alpha \mathrm{Cr}$ and its role in the embrittlement of alloy 718 .

\section{Experimental}

Samples of alloy 718 from retired longtime service disks and samples isothermally exposed up to 50,000 hours in a temperature range of $539^{\circ} \mathrm{C}$ to $704^{\circ} \mathrm{C}$ were re-evaluated for $\alpha \mathrm{Cr}$ formation using a modified electrolytic preparation technique. Both extraction of phases and $\mathrm{x}$ ray analyses and SEM techniques were carried out to detect the start of $\alpha \mathrm{Cr}$ formation and growth with exposure times.

\section{Results}

Past metallographic studies on longtime exposed samples of alloy 718 wcrc carried out on electropolished and electro-etched surfaces. This preparation puts the MC, TiN, $\delta$, and $\gamma^{\prime \prime} / \gamma^{\prime}$ phases in relief while etching out the $\alpha \mathrm{Cr}$ and sigma phases. The presence of $\alpha \mathrm{Cr}$ was thus determined by holes in the microstructure. The beginning of $\alpha \mathrm{Cr}$ precipitation was difficult to detect when large amounts of other phases formed during long exposures at $649^{\circ} \mathrm{C}$ and $704^{\circ} \mathrm{C}$.

To detect the onset of $\alpha \mathrm{Cr}$ formation, the samples were re-electropolished for 15 seconds to put the $\alpha \mathrm{Cr}$ in relief and examined without etching. The $\alpha \mathrm{Cr}$ phase was verified by EDS analyses of the particles. However, to further confirm such particles as the $\alpha \mathrm{Cr}$ phase, an area was photographed before and after the electro etch to confirm the holes as the location of $\alpha \mathrm{Cr}$ particles.

Figure 1 shows the same area before and after etching in the rim area of a 15,000 hours retired alloy 718 disk. Figure 1a shows the presence of many $\alpha \mathrm{Cr}$ particles in relief while Figure $1 \mathrm{~b}$ shows holes corresponding to the $\alpha \mathrm{Cr}$ particles after $\mathrm{a} \mathrm{CrO}_{3} \mathrm{ctch}$. X-ray analysis of extracted residue showed a strong $\alpha \mathrm{Cr}$ phase to be present.

$\mathrm{CrO}_{3}$ etched samples of alloy 718 which were exposed at $593^{\circ} \mathrm{C}, 649^{\circ} \mathrm{C}$, and $704^{\circ} \mathrm{C}$ were studied for holes indicating $\alpha \mathrm{Cr}$ formation. Appreciable $\alpha \mathrm{Cr}$ particles were found in samples exposed at $593^{\circ} \mathrm{C}$ for $50 \mathrm{Kh}, 5 \mathrm{Kh}$ and longer at $649^{\circ} \mathrm{C}$ and $1 \mathrm{Kh}$ and longer at $704^{\circ} \mathrm{C}$. X -ray studies confirmed the increase of $\alpha \mathrm{Cr}$ with time and at elevated temperatures.

Selected as electropolished samples of isothermally exposed and retired disk samples were studied using SEM and EDS techniques. Results of representative structures are presented in Figures 2-5. Figure 2 shows an increase of $\alpha \mathrm{Cr}$ with increased exposure time at $649^{\circ} \mathrm{C}$. The $\alpha \mathrm{Cr}$ at $704^{\circ} \mathrm{C}$, Figure 3, appears to be larger but fewer in number and there is evidence of sigma phase presence. More $\alpha \mathrm{Cr}$ appears and an accicular structure became more evident with increased time at $704^{\circ} \mathrm{C}$.

The phases found in a sample tested at $733^{\circ} \mathrm{C}$ for 5400 hours appeared to be both $\alpha \mathrm{Cr}$ and sigma phase, Figure 4 . Figure 5 shows varying $\alpha \mathrm{Cr}$ structures in the rim areas of retired 718 disks which have had 15,000 and 28,000 hours of engine exposure. A needle shaped phase as well as discrete particles appear in the 15,000 hour disk sample while more discrete $\alpha \mathrm{Cr}$ particles appear in the 28,000 hour sample. While there appears to be good correlation for more $\alpha \mathrm{Cr}$ formation with increased exposure time, the question of how much $\mathrm{Cr}$ is necessary for $\alpha \mathrm{Cr}$ 


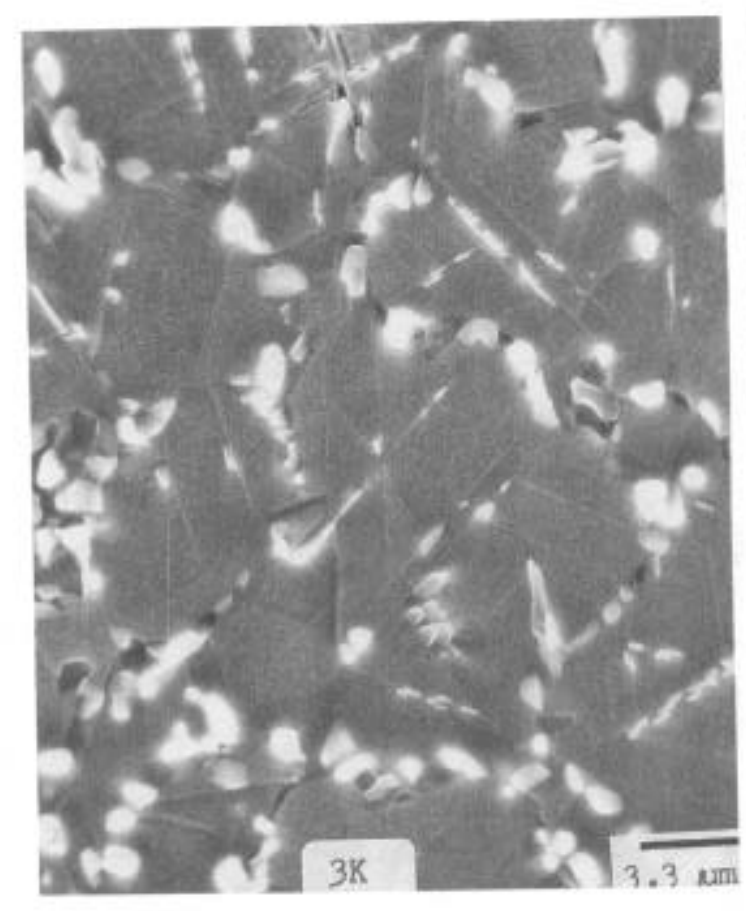

Before

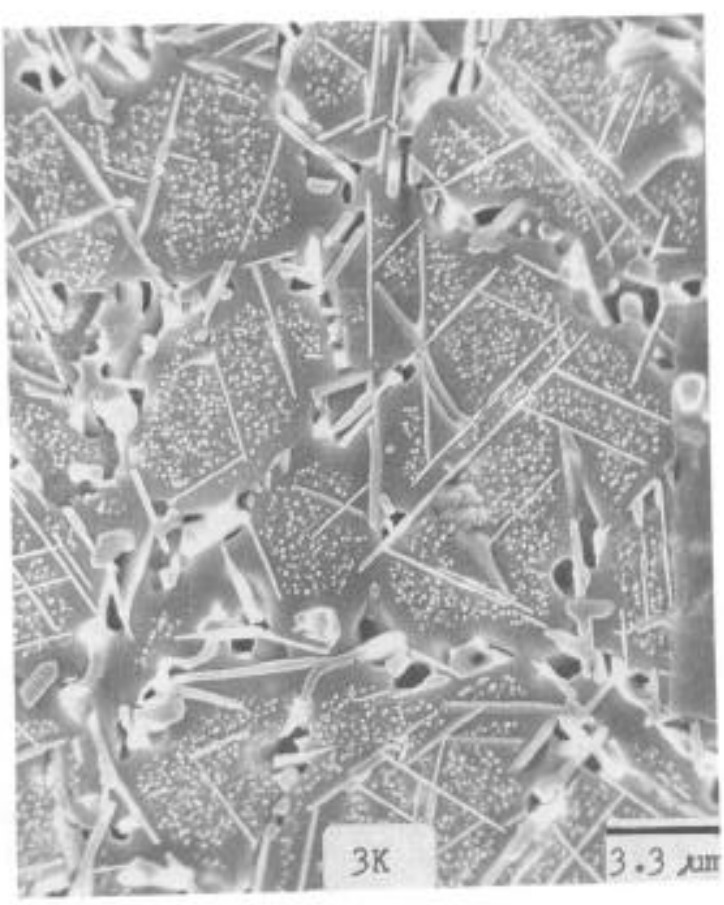

After

Figure 1 acr Phase in a 15,000h Disk Before and After Etching

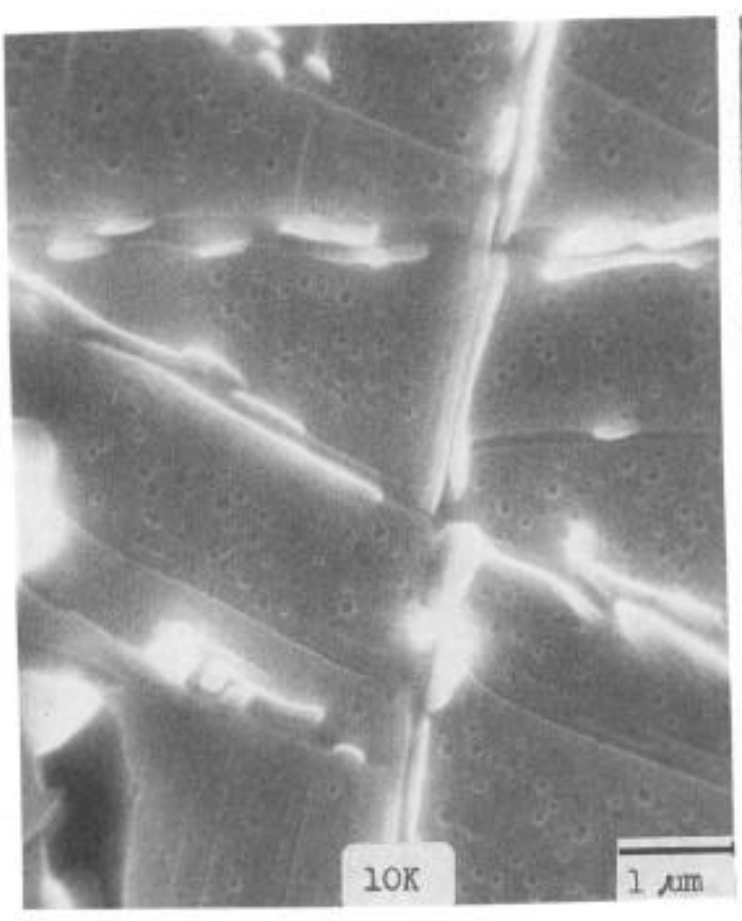

Before

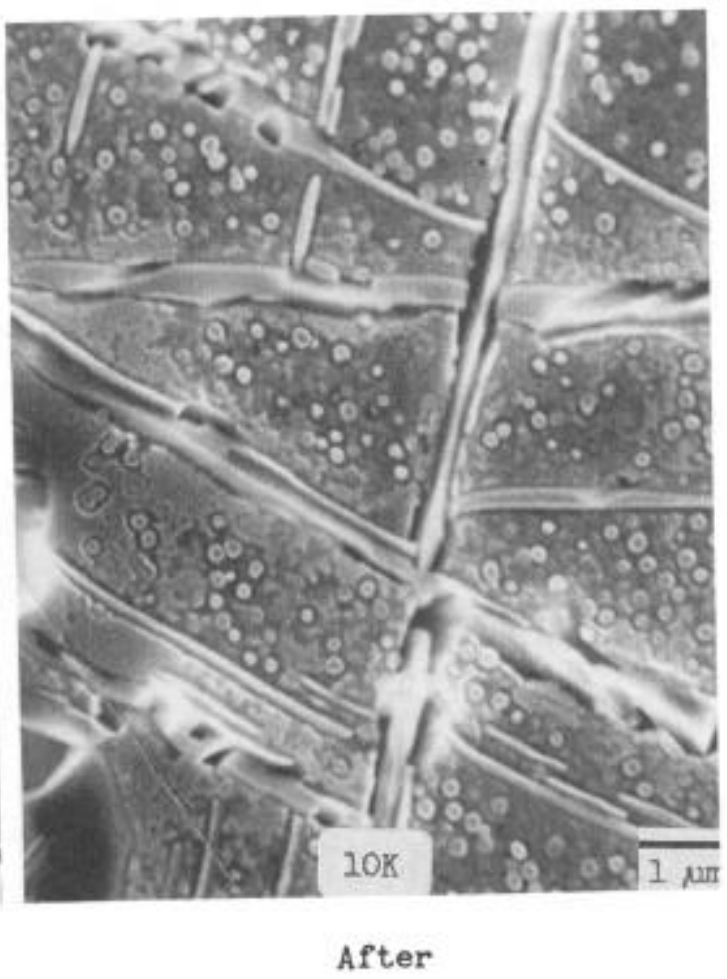

After 


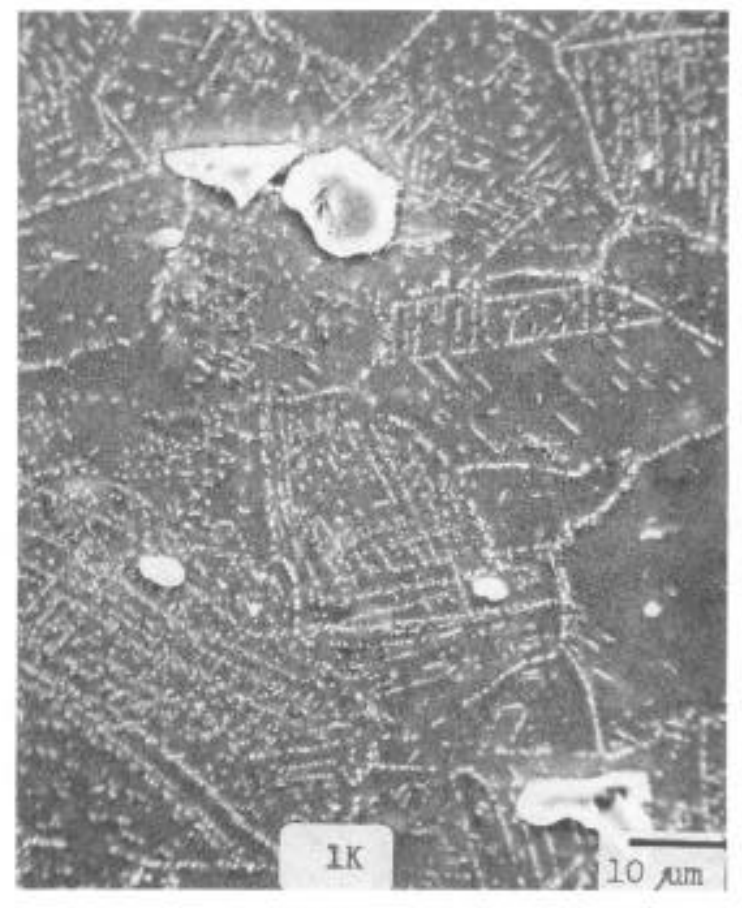

$5 \mathrm{Kh}$

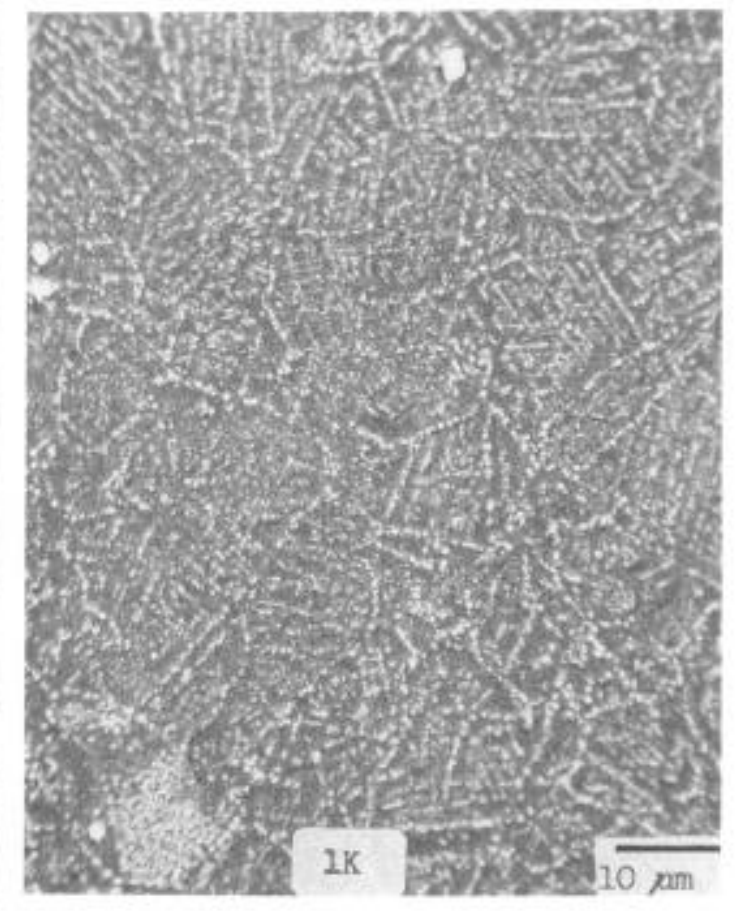

$10 \mathrm{Kh}$

Figure $2 \alpha \mathrm{Cr}$ Phase After $5 \mathrm{Kh}$ and $10 \mathrm{Kh}$ Exposures at $64^{\circ} \mathrm{C}$

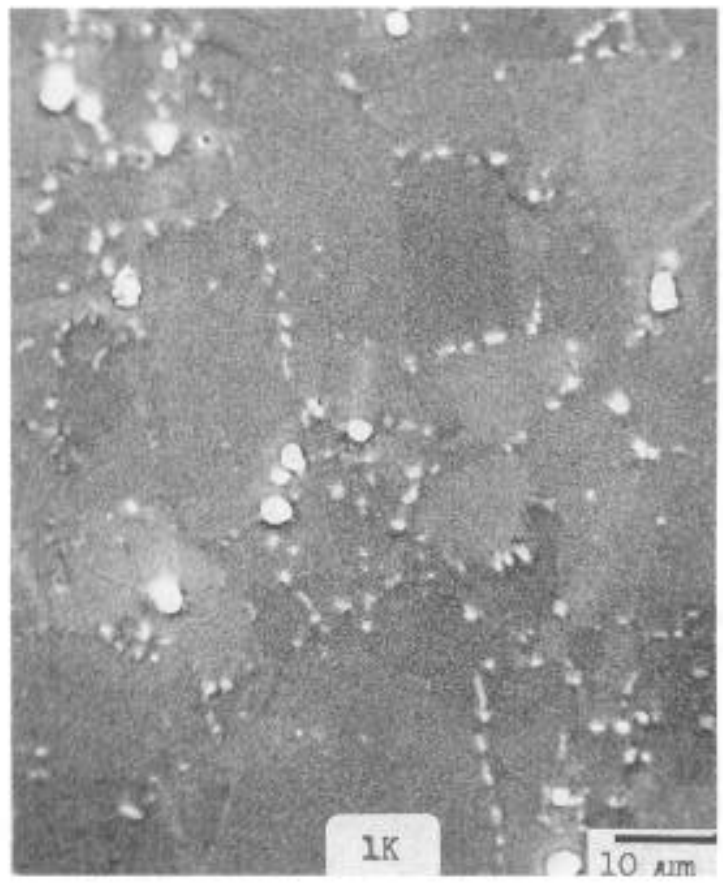

$5 \mathrm{Kh}$

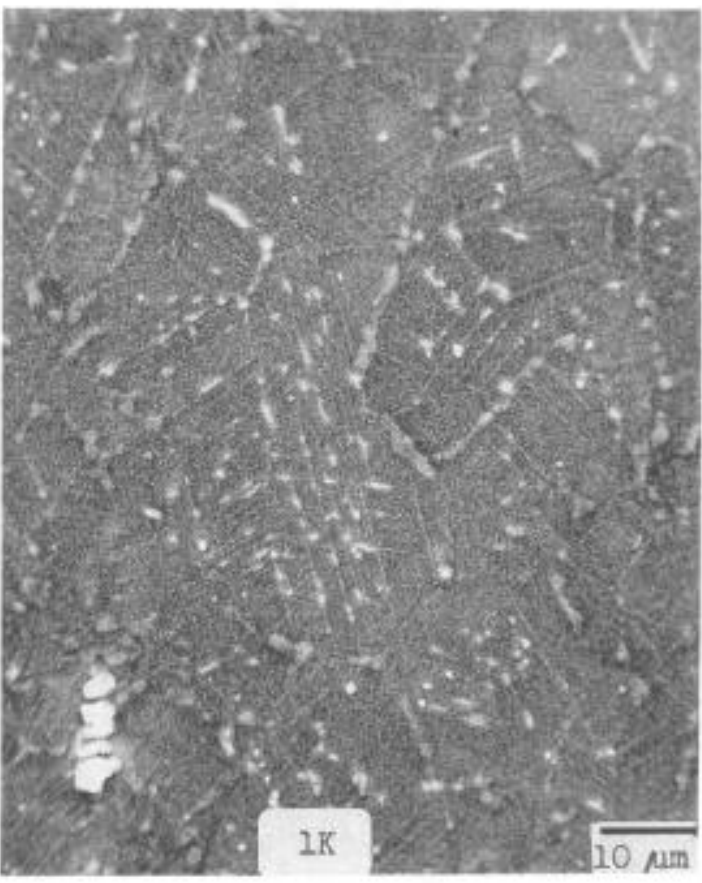

$25 \mathrm{Kh}$

Figure $3 \mathrm{aCr}$ Phase After $5 \mathrm{Kh}$ and $25 \mathrm{Kh}$ Exposures at $704^{\circ} \mathrm{C}$ 

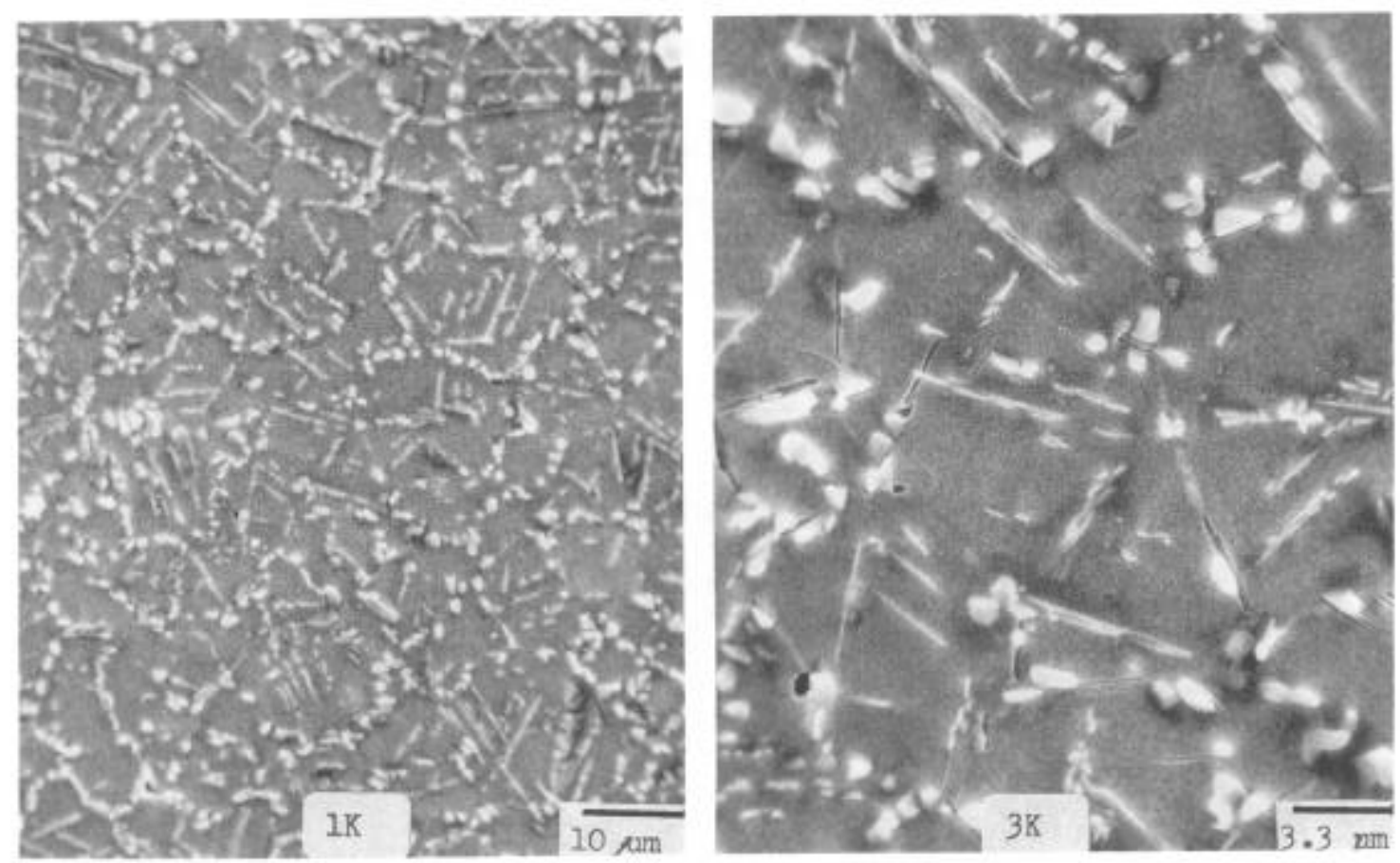

Figure $4 \alpha \mathrm{Cr}$ in a $S / R$ Test of $5400 \mathrm{~h}$ at $733^{\circ} \mathrm{C}$

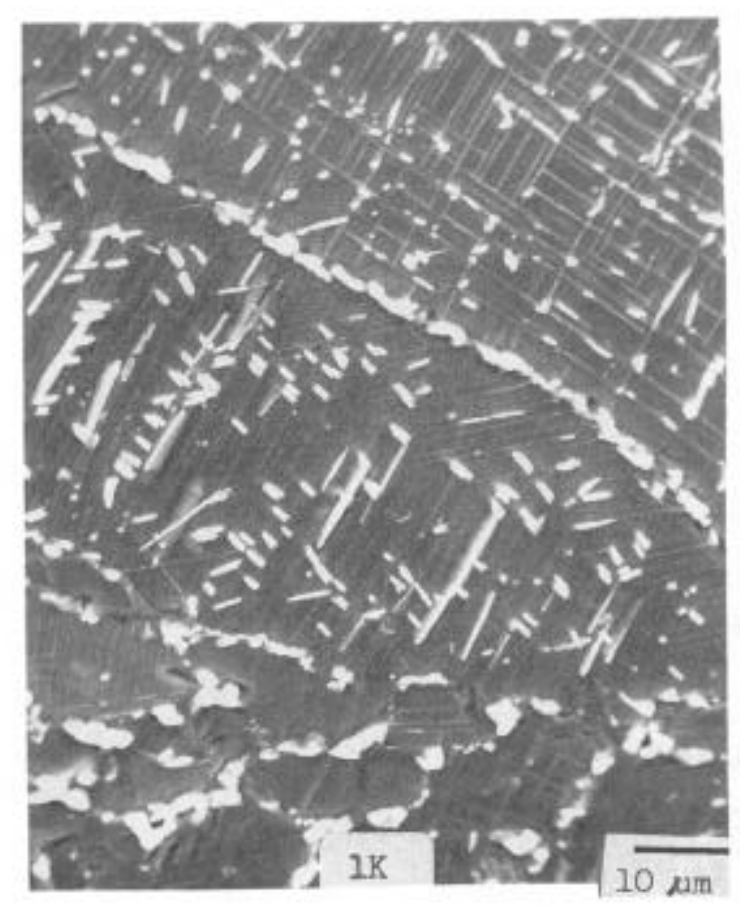

$15 \mathrm{Kh}$

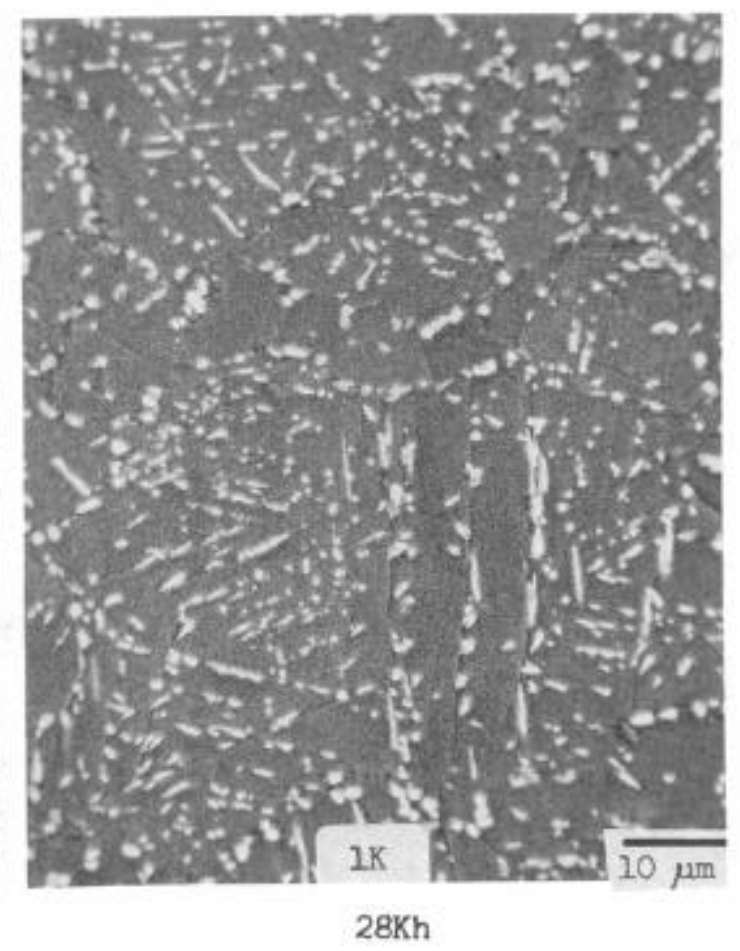

Figure 5 aCr Precipitation in Retired Long Time Disks 


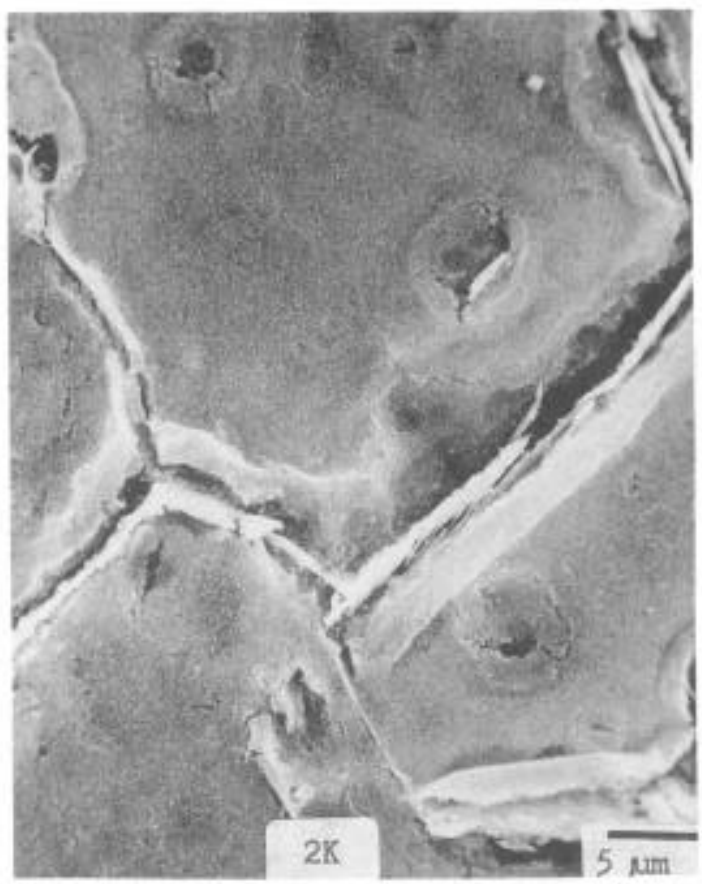

$623^{\circ} \mathrm{C} / 50 \mathrm{Kh}$

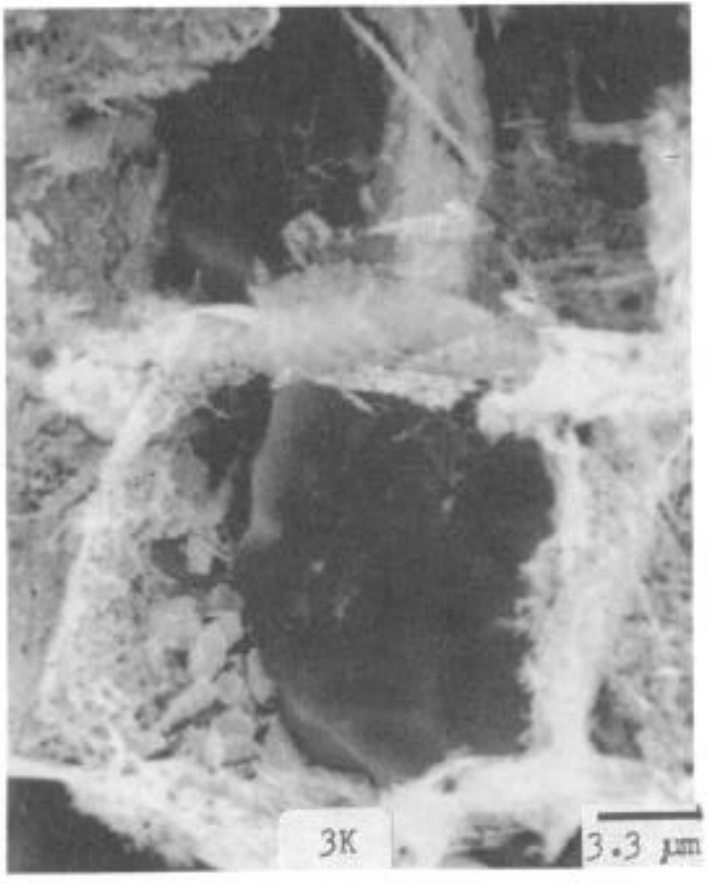

$649^{\circ} \mathrm{C} / 1 \mathrm{Kh}$

Figure 6 Grain Boundary aCr Films after Long Time Exposures

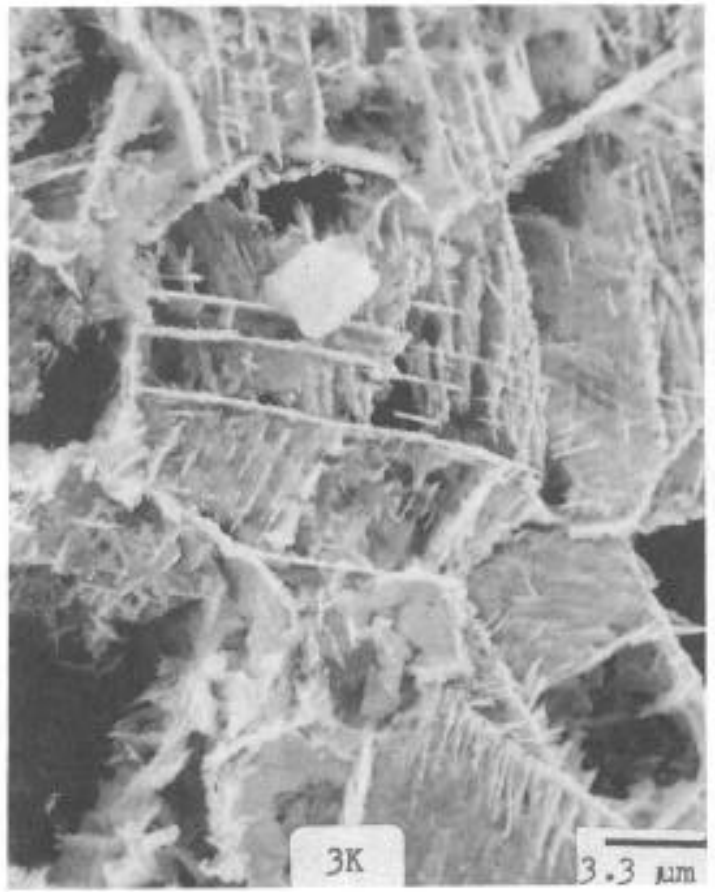

$649^{\circ} \mathrm{C} / 5 \mathrm{Kh}$

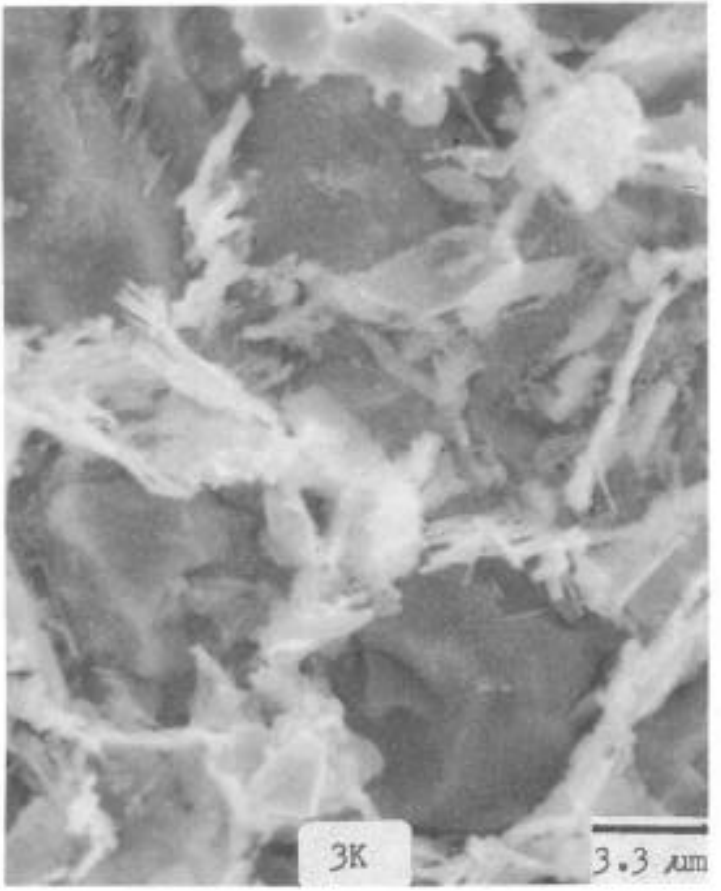

$704^{\circ} \mathrm{C} / 1 \mathrm{Kh}$ 
formation needs to be addressed. Since $649^{\circ} \mathrm{C}$ appears to be a critical temperature for formation of $\alpha \mathrm{Cr}$, a sample of PWA1472 with $12 \% \mathrm{Cr}$ was evaluated after an exposure of 1200 hours at $680^{\circ} \mathrm{C}$. No $\alpha \mathrm{Cr}$ precipitation was found with this $\mathrm{Cr}$ level which agrees with the results found in ferritic steels.

Because there appears to be non-uniform precipitation of $\alpha \mathrm{Cr}$ as seen in Figure $2 \mathrm{a}$, a sample of spray cast plus HIP alloy 718 was exposed for 1000 hours at $649^{\circ} \mathrm{C}$ and evaluated for $\alpha \mathrm{Cr}$. No $\alpha \mathrm{Cr}$ precipitation was found which suggests that $\mathrm{Cr}$ segregation plays a role in the formation of the $\alpha \mathrm{Cr}$ phase.

\section{Discussion of Results}

From $\mathrm{x}$-ray studies of extracted residues, no $\mathrm{Cr}$ carbide phase is found but only the $\alpha \mathrm{Cr}$ phase at the lower temperature while sigma phase begins to form at $704^{\circ} \mathrm{C}$. The $\alpha \mathrm{Cr}$ phase is found in both retired disks and isothermally aged samples and increases in amount as exposure time increases.

From metallographic evaluations, the $\alpha \mathrm{Cr}$ phase appears to be associated with the delta phase whether the delta phase is in the grain boundaries or in the grains. While this suggests that the formation of delta phase produces local enrichment of $\mathrm{Cr}$ and the formation of $\alpha \mathrm{Cr}$, the drop in impact strength in relatively short exposure times suggests that detrimental grain boundary structures have begun to grow. In Ni base alloys, such structures generally are continuous grain boundary $\mathrm{Cr}$ carbide films.

To verify the presence of grain boundary films, samples exposed at $623^{\circ} \mathrm{C}$ for $50 \mathrm{Kh}, 1$ $\mathrm{Kh}$ and $5 \mathrm{Kh}$ at $649^{\circ} \mathrm{C}$, and $1 \mathrm{Kh}$ at $704^{\circ} \mathrm{C}$ were given an electrolytic etch in $10 \% \mathrm{HCl}$-methanol and re-examined on the SEM. Extensive grain boundary films were found.

Figure 6 shows the growth of grain boundary films in the various exposed samples. EDS analysis of the films show very strong $\mathrm{Cr}$ with a small amount of $\mathrm{Nb}$ which identifies the films as $\alpha \mathrm{Cr}$.

\section{Conclusions}

1. $\alpha \mathrm{Cr}$ is the only $\mathrm{Cr}$ rich phase which forms in a temperature range of $539^{\circ} \mathrm{C}$ to $649^{\circ} \mathrm{C}$ while sigma phase is found at higher temperatures.

2. The $\alpha \mathrm{Cr}$ formation is associated with delta phase formation due to $\mathrm{Cr}$ enrichment as $\mathrm{Ni}$, $\mathrm{Al}$, and $\mathrm{Nb}$ are depleted from the matrix.

3. The conventional metallographic techniques do not show the true $\alpha \mathrm{Cr}$ morphology as does the electrolytic technique.

4. $\alpha \mathrm{Cr}$ films at the grain boundaries appear to be the cause of the loss of impact strength in longtime exposures at $623^{\circ} \mathrm{C}$ to $704^{\circ} \mathrm{C}$.

\section{References}

1. R. M. Fisher, E. J. Dulis, and K. G. Carroll, "Identification of the Precipitate Accompanying $885^{\circ} \mathrm{F}$ Embrittlement in Chromium Steels," Journal of Metals, May 1953.

2. Gary E. Korth, "Mechanical Properties Test Data of Alloy 718 for Liquid Metal Fast Breeder Reactor Applications," U.S. Department of Energy Report, EG\&G Idaho, Inc., Jan. 1983.

3. J. F. Radavich and G. E. Korth, "Effects of Very Long Time Aging in Alloy 718," TMS Annual Meeting, San Diego, CA, 1992. 